\title{
GEOMATIC ARCHAEOLOGICAL RECONSTRUCTION AND A HYBRID VIEWER FOR THE ARCHAELOGICAL SITE OF CÁPARRA (SPAIN)
}

\author{
C. Tejeda-Sánchez ${ }^{1}$, A. Muñoz-Nieto ${ }^{1, *}$, P. Rodríguez-Gonzálvez ${ }^{2,3}$ \\ ${ }^{1}$ Department of Land and Cartographic Engineering, High Polytechnic School of Avila, University of Salamanca, Spain - \\ ctejsan@gmail.com,almuni@usal.es \\ ${ }^{2}$ Department of Mining Technology, Topography and Structures, Universidad de León, Ponferrada, Spain - p.rodriguez@unileon.es \\ ${ }^{3}$ TIDOP Research Group, University of Salamanca, Spain
}

Commission II, WG II/8

KEY WORDS: Photogrammetry, Reconstruction, Archaeology, GIS

\begin{abstract}
:
Visualization and analysis use to be the final steps in Geomatics. This paper shows the workflow followed to set up a hybrid 3D archaeological viewer. Data acquisition of the site survey was done by means of low-cost close-range photogrammetric methods. With the aim not only to satisfy the general public but also the technicians, a large group of Geomatic products has been obtained (2d plans, 3d models, orthophotos, CAD models coming from vectorization, virtual anastylosis, and cross sections). Finally, all these products have been integrated into a three-dimensional archaeological information system. The hybrid archaeological viewer designed allows a metric and quality approach to the scientific analysis of the ruins, improving, thanks to the implementation of a database, and its potential for queries, the benefits of an ordinary topographic survey.
\end{abstract}

\section{INTRODUCTION}

Geomatics incorporate a set of techniques whose purpose is the measurement, analysis, management and representation of spatial data. The use of referenced spatial data is common in many and varied disciplines: cartography, engineering, agronomy, energy, mining, architecture, etc. In some of them the use of spatial data has an intrinsic character as is the case of Architecture and Archaeology. This is due to the fact that spatial data is vital for the design of new buildings or for the analysis and interpretation of archaeological remains.

Present work is part of a line of applications of Geomatics in Archaeology and Architecture. The tasks of representation and three-dimensional modelling of archaeological and architectural heritage have a long tradition in the Scientific Community. The aim of these works has been, in general terms, the documentation, analysis, dissemination and preservation of heritage assets. In this way, over the years, Geomatics has had the opportunity to check, on different types of remains and ruins, the performance of new sensors and equipment, as well as the usefulness of their methods and work procedures.

The instrumentation and Geomatics methodologies applied to Archaeology have undergone a remarkable evolution in the last decades, in which it has gone from the quasi-manual methods of surveys by classical topography, to the most recent automatic photogrammetric techniques or to the use of the terrestrial laser scanner (TLS) and other modern sensors. In contrast with the selective character of traditional methods, the newest spatial information acquisition techniques are characterized by carrying out massive data records, with a remarkable precision. This offers remarkable advantages when it comes to analysing a-posteriori the objects represented and drawing conclusions related to geometry or its qualitative properties (colour, texture, materials).
Once the 3D models have been obtained, Geomatics offers a step forward and brings the opportunity to incorporate metric information into spatial information systems that facilitate the management of architectural or archaeological remains. In this sense it is intended that these systems are able to integrate data coming from different sensors and collected by different techniques in different moments: either from excavation campaigns conducted in the past, or from those that can be scheduled in the future. Thereby the information system will serve as a support for the decision making in a technical way, by architects and archaeologists. In this sense, there are several works that have been carried out.

This article proposes to carry out the photogrammetric survey and the implementation of a hybrid viewer derived from a classic Geographical Information System (GIS) as well as the reconstruction and modelling of $3 \mathrm{D}$ objects of the Roman site of Cáparra. The aim of the Geomatic products is to be multipurpose, being useful both for researchers and technicians, in their conservation and restoration tasks, as well as for the general public. Geographical Information Systems (GIS) are the natural framework to gather and manage archaeological data. Besides the spatial indexing and querying database possibilities, the third coordinate was a relevant element, which had to be included in the system to improve it in terms not only of quality, completeness and realism but to facilitate the decision making in management processes. In an archaeological study case, the survey involves a $3 \mathrm{D}$ documentation, no matter the technique employed (TLS, photogrammetry...). The possibility of collecting all kind of datasets, both existing ones and those generated at the moment or in the future, in a common database, and incorporate them into an application, will allow to generate a historical/heritage information system (Nocerino et al., 2018). This information system can be used in a simple way by general public as scholars i.e. by means of a web platform, or in a more

* Corresponding author 
sophisticated way, for researching purposes, or by stakeholders for management purposes.

\section{AREA OF STUDY}

The Roman city of Cáparra is located in Extremadura (Spain) in the north of the province of Cáceres, near the city of Plasencia, on the margins of the Ambroz valley, and on the municipal districts of Oliva de Plasencia and Guijo de Granadilla (Figure 1). The archaeological site extends over an area of approximately 15 hectares and presents a set of remains of walls, buildings and monumental elements, in granite and marble, which have been documented during various excavation campaigns (Floriano, 1944) (Blazquez, 1996) (Cerrillo et al., 2000). More concretely, there were excavated parts of the forum $(0.4 \mathrm{ha})$, thermal baths $(0.4 \mathrm{ha})$ and the domestic area ( $0.1 \mathrm{ha})$, along with three necropolises outside the city. The city of Cáparra, which had its greatest splendour during the 1 st and 2 nd centuries $\mathrm{AD}$, was part of the Roman province of Lusitania and occupied a strategic position on the so-called Via de la Plata (silver route) that crosses it through its decumanus maximus (longitudinal axis) from north to south. This road of $2.5 \mathrm{~m}$ wide crossed the city has a total length of $558 \mathrm{~m}$ inside the city (limited by a pentagonal wall).

Among all the archaeological remains stands out, for its state of conservation and emblematic character, the Tetrapylon, or quadrifronte, (popularly known as the Cáparra arch). It is a quadruple monumental arc, located in the centre of the site, where probably the main streets of the municipality, the cardo (transverse axis) and the decumanus, very close to the forum and other public buildings. It consists of four pillars made of granite ashlars and core of opus caementicium or Roman concrete, (from the Latin = caementum: rubble, rough stone), a type of work made of mortar and stones of all kinds (waste, example) and that has the appearance of concrete. These four pillars give way to four arcs facing two to two. From these same four pillars, an arched vault that supports an attic, is the most deteriorated area today. Two of these pillars served as a support for two inscriptions. Only one of them is preserved today. This four-sided arch is unique in Spain.

The first archaeological works began at 1929 (Floriano, 1944). Cáparra was mentioned as a city by Plinio ( $1^{\text {st }}$ century a.D) and by Ptolomeo ( $2^{\text {nd }}$ century a.D) and in Renaissance times by Accorsi (1527) and Momeranus among others (Floriano, 1944). The major excavations campaigns took place in 2001, with the aim to adapt the site for touristic purposes and the construction of the interpretation centre (Belloso, 2007).

\section{METHODOLOGY}

The generation of the hybrid viewer has two main steps. The first one is related to the $3 \mathrm{D}$ reconstruction of the archaeological site. The second one is the implementation of the viewer itself. While both are interrelated, before describing it, we proceed to describe the workflow followed, as illustrated in Figure 2.

Previous considerations were done in the beginning to choose the most convenient methodology and instrumentation according to the casuistry of the case study. To this end, terrestrial photogrammetry was contrasted with aerial photogrammetry and laser scanning in terms of compare advantages and disadvantages and quality assessment. This question is not new, since every acquisition technique presents some limitations, being their intercomparison a not trivial task since the acquisition protocol is intimate relate to the particularities of the study case (Grussenmeyer et al., 2008). In the case of aerial photogrammetry from drones, it is possible to provide $3 \mathrm{D}$ products in large scale that satisfy the archaeologist analysis requirements, while at the same time is generated a dataset which can be used for other purposes such as touristic promotion, heritage preservation or web dissemination (Hernández-Fernandez et al., 2015) (Torres-Martínez et al., 2016). However, as shown in the aforementioned study, the covered area has to be large to be efficient (in that example 30 ha). For area-limited study cases, or sites which do not fulfil the 2.5D constraint, the advisable Geomatic techniques are ground based. In Nocerino et al. (2014) a comparison between laser scanner and terrestrial photogrammetry, for archaeological cases, is carried out. In the study is highlighted that a proper camera network geometry, as well as the inclusion of convergent images avoid the presence of deformations in the 3D photogrammetric model. So, a correct planning of the camera network is crucial to achieve accurate results (Nocerino et al., 2014).

Based on these recommendations, terrestrial photogrammetry was chosen as the acquisition method, given the adequate precision expected in planimetric, the high density of points and the continuous coverage that could be obtained.

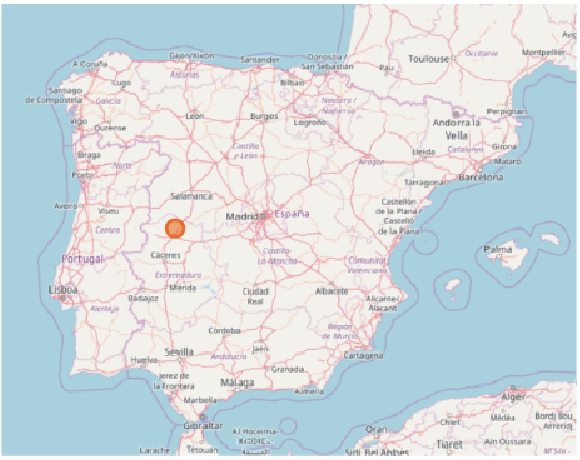

(a)

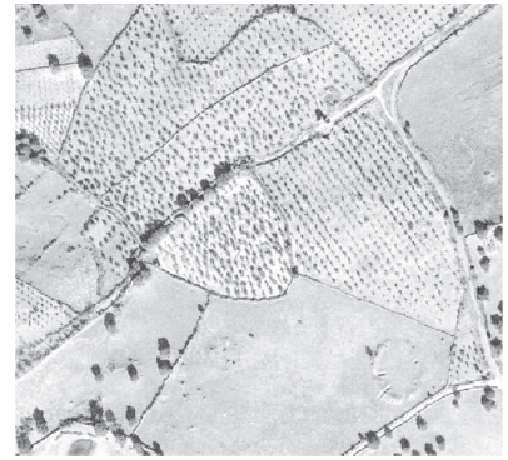

(b)

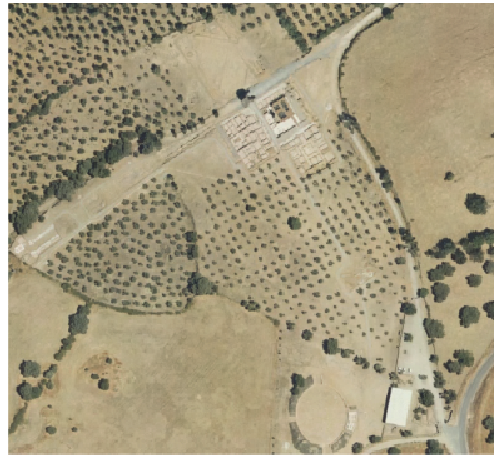

(c)

Figure 1. Situation map of the Roman City of Cáparra. (a) General view (source: OpenStreeMap). (b) Detail view: Aerial photograph from the interministerial flight 1973-1986 (Source: Instituto Geográfico Nacional). (c) Detail view: Orthomosaic from 2012 PNOA campaign (Source: Instituto Geográfico Nacional). 


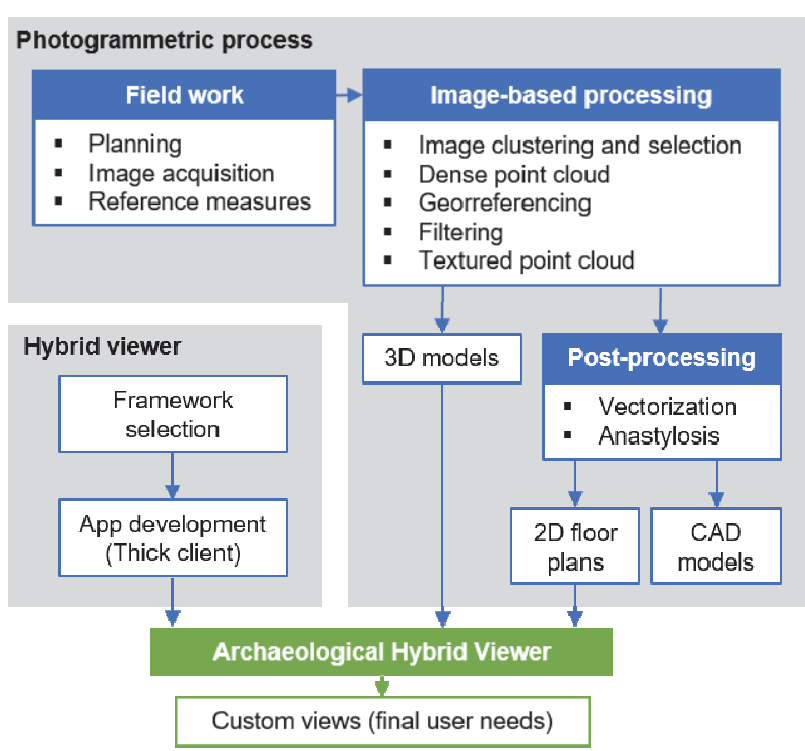

Figure 2. Workflow.

As can be seen in Figure 2, the photogrammetric workflow consists of two phases, the data capture phase in the field and its subsequent processing in the laboratory. In the first one, a preliminary analysis was carried out leading to the planning of photographic shots in order to achieve the aimed precision. While in the second one the search will be made for the elements that will be integrated in the final viewer as geospatial layers.

\subsection{Image-based reconstruction pipeline}

Next, the workflow carried out to get the 2D and 3D products is described. Since there was followed a classic approach for the photogrammetric reconstruction, only the more relevant issues in an archaeological context are described.

3.1.1 Preplannig: The previous planning phase included both the establishment of the work strategy and the decision between establishing a single global cluster, or individualizing them according to the nature of the different remains in terms of shape distributions lengths or heights. Another of the issues addressed was the well-known problem of scaling the resulting models to give them the adequate precision for the final purpose of visualization and dissemination.

The planning of the photogrammetric network is a critical element to guarantee the final precision of the 3D reconstruction. Following the approach of low cost (without the need for drones), we opted for the strategy of making the photogrammetric acquisition. To this purpose we follow a scheme of rings or image cluster, distributing them in the 5 clusters whose allocation along the remains is shown in Figure 3. A $30 \%$ overlap of parallel images was considered.

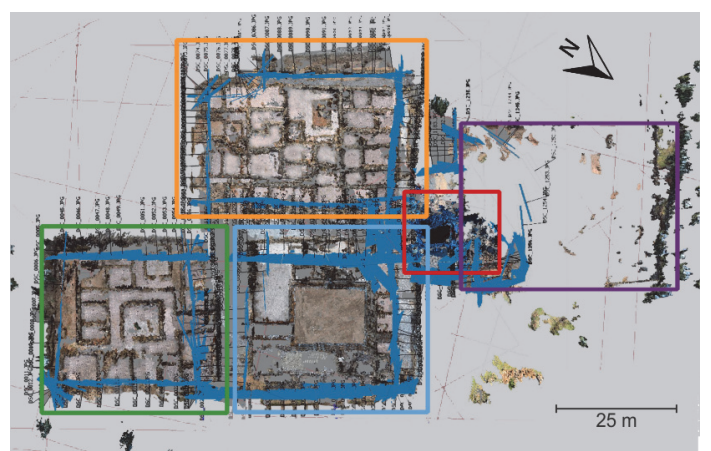

Figure 3. Image clusters employed for the archaeological case.

As a photographic sensor, a Nikon D3300 SLR camera (Table 1) was used in manual mode to control the exposure of the images. The recommendations of work were the use of the focal point with the highest possible field of view $(18 \mathrm{~mm}$ in this case), with fixed focus to infinity to avoid changes in the internal calibration of the camera. Regarding the capture, this was done under cloudy day conditions, but without direct sun, so that the ISO sensitivity was as low as possible (between 100 and 200) in order to reduce the noise generated.

\begin{tabular}{lc}
\hline Parameter & Value \\
\hline Sensor type & CMOS \\
Sensor size & $23.5-15.6 \mathrm{~mm}$ \\
Effective pixels & $24.2 \mathrm{Mp}$ \\
Pixel size & $3.9 \mu \mathrm{m}$ \\
Lens & $18-55 \mathrm{~mm}$ \\
\hline
\end{tabular}

Table 1. Camera technical specifications

Likewise, we would remark that in order to simulate the most usual working conditions, a self-calibration field was chosen. This is a real situation in which the same camera is used for various purposes such as, 3D reconstruction of remains and/or constructions, but at the same time to register fine details. This implies a change in the internal camera calibration coefficients. The parameters of internal orientation were determined in a specific cluster, given that its geometry allowed to establish a more robust network with depth changes. These parameters were applied together for all working clusters.

Finally, we have to make a decision about what geomatics technique would be the best to give scale to the obtained photogrammetric models. Following the approach of low cost and most generalizable methodology possible, it was decided to determine spatial invariants of distance using a distancemeter. In total there were acquired 20 distance measurements using the natural features of the archaeological remains, as it is shown in Figure 4.

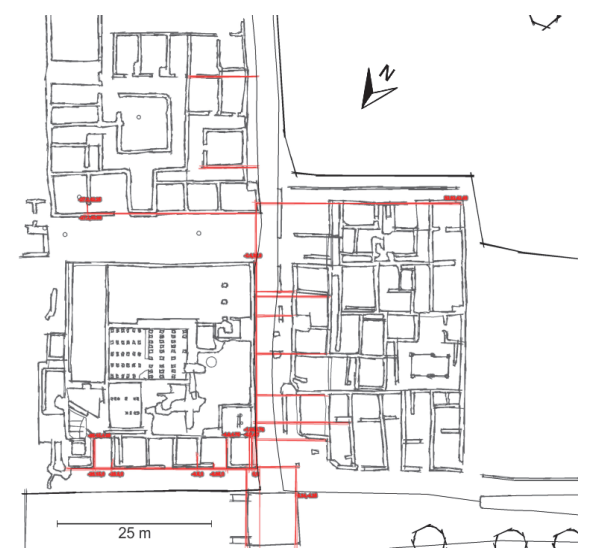

Figure 4. Distribution of image measurements. 
3.1.2 3D reconstruction: The photogrammetric processing begins discarding those images that are redundant or have a poor image quality due to problems of overexposure, underexposure, shadows, etc. The images that maintain a minimum quality are divided into different clusters as discussed in the previous subsection. One of the clusters was initially processed to determine the self-calibration parameters, which would be used as initial approximations in the rest. The alignment was carried out by SfM implementation of Agisoft Photoscan (Agisoft, 2018). However, in the processing of some clusters, alignment problems were detected, so that it was decided to subdivide the rings into smaller areas, according to faces or facades, and to make consecutive alignments between them until completing the initial planning. This iterative strategy supplements the limitations, or lack of robustness, of the tiepoint detector algorithm, due to changes in perspective. The different clusters were referenced by the common tiepoints, so that after the phase of alignment or orientation, a dense cloud of points was obtained, with a total of 13.2 million points (Figure 5).

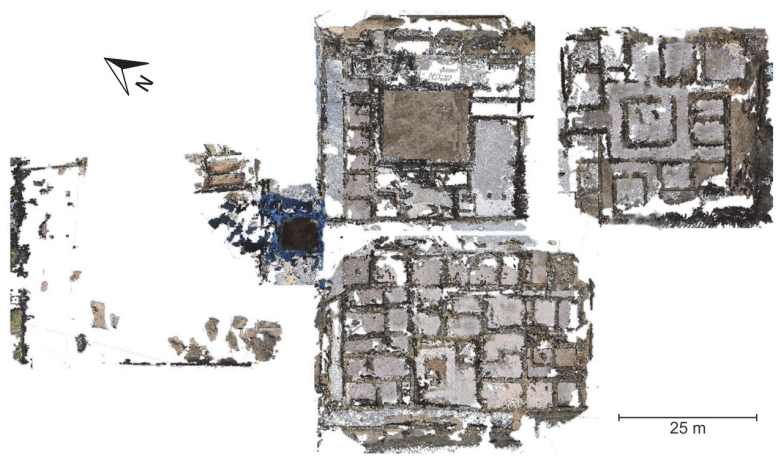

Figure 5. Nadiral view of the dense point cloud.

Finally, indicate that the 3D models obtained, as well as the derived products and thematic maps, are defined in a local system and a georeferencing is necessary to be able to overlap them with other WMS layers. Although the GNSS integrated in the smartphones allow metric precision for a coarse georeferencing, a more generalizable methodology with more control was chosen, such as cartographic orientation by the selection of coplanar points. According to the specifications of Spanish National Plan of Aerial Photography (PNOA, 2018) for the flight of $50 \mathrm{~cm}$, the planimetric accuracy of the orthophoto is $\pm 1.00 \mathrm{~m}$, while its associated terrain model has an accuracy of $\pm 2.00 \mathrm{~m}$

3.1.3 Post-processing: Finally, filtering and vectorization is carried out in order to obtain elevations and sections that will form a series of geospatial layers to be added to the final viewer, and which will also serve as a basis to carry out a virtual anastylosis process. Given the large size of the final point cloud, it was necessary to filter it before its incorporation into the information system database in order to improve processing costs. This operation was carried out in CloudCompare software (CloudCompare, 2018).

Finally, and to conclude, the process of virtual anastylosis, vectorization of the different vertical elements is performed, highlighting the tetrapylon, which will also serve as a graphic element to document its current status and serve as a means for rehabilitation actions (Figure 6). From the current state, along with the original descriptions and pre-existing documentation anastylosis is performed (Figure 7).

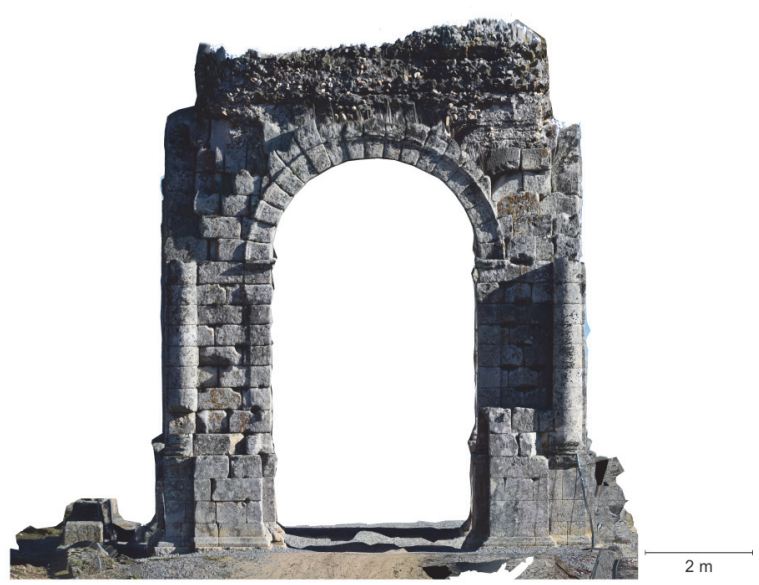

Figure 6. Elevation view of the Tetrapylon.

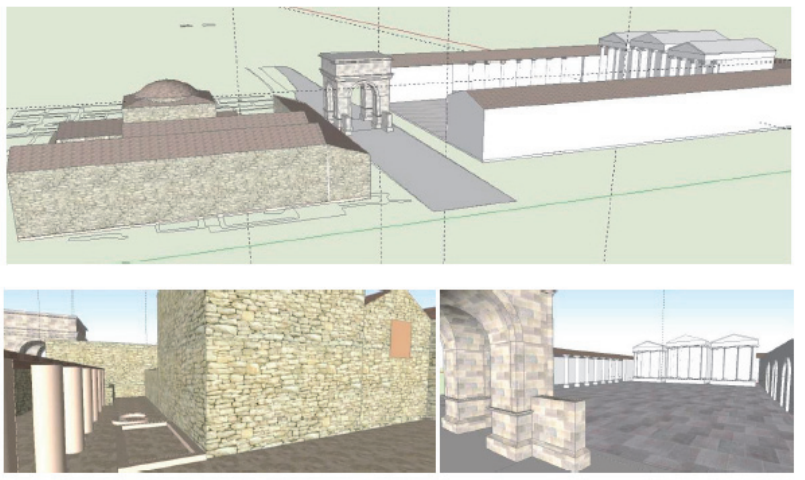

Figure 7. Final results of the virtual anastylosis.

\subsection{Hybrid viewer}

The next challenge that was raised in this project was the realization of a viewer that was able to connect and manage the $2 \mathrm{D}$ and $3 \mathrm{D}$ information obtained. It was intended that each layer had a connection relationship with its point cloud and with the elevations and sections obtained. The proposed application should have the functionalities of a database in which all data can be lodged in an organized and connected way and on which technical queries can be made and visualize the results. Our approach was conditioned by the search of a final solution that did not need any additional software.

Given the shortcomings detected to achieve these purposes with the existing software, we consider the development of an own application, selecting as $\mathrm{C}++$ coding language for the possibility of taking advantage of the multiple external libraries existing in this field of application. The final implementation of the system required the use of several software applications as detailed in the following table (Table 2).

\begin{tabular}{lc}
\hline Element & Description \\
\hline Qt 4.8.4 & General libraries \\
Qt Creator 2.6.0 & App developer \\
Windows SDK & Debugger \\
Visual Studio 2010 & Compiler \\
CMake 3.5.2 & Build system \\
QGIS Brighton 2.6 & GIS libraries \\
VTK 5.8.0 & Point cloud libraries \\
\hline
\end{tabular}

Table 2. Software and libraries employed.

The final viewer involved the use of several functions. In table 3 are listed the employed in the case of QGIS (QGIS, 2018) and VTK (Schroeder et al., 2006) (VTK, 2018). The Qt libraries 
(Qt, 2018) were employed to design the Graphical User Interface.

\begin{tabular}{|c|c|c|}
\hline Lib. & Functions & Description \\
\hline QGIS & $\begin{array}{l}\text { qgsapplication } \\
\text { qgslayertreemapcanvasbridge } \\
\text { qgslayertreemodel } \\
\text { qgslayertreeview } \\
\text { qgsmapcanvas } \\
\text { qgsmaplayerregistry } \\
\text { qgsmaptool } \\
\text { qgsmaptoolpan } \\
\text { qgsmaptoolzoom } \\
\text { qgsproject } \\
\text { qgsproviderregistry } \\
\text { qgssinglesymbolrendererv2 } \\
\text { qgsvectorlayer }\end{array}$ & $\begin{array}{l}\text { - Create layers } \\
\text { - Create the layer tree } \\
\text { - Create the viewer } \\
\text { - Create tools to } \\
\text { manipulate the map } \\
\text { - Start the application }\end{array}$ \\
\hline VTK & $\begin{array}{l}\text { vtkActor } \\
\text { vtkCellArray } \\
\text { vtkPointData } \\
\text { vtkPoints } \\
\text { vtkPolyData } \\
\text { vtkPolyDataMapper } \\
\text { vtkProperty } \\
\text { vtkRenderer } \\
\text { vtkRenderWindow } \\
\text { vtkRenderWindowInteractor } \\
\text { vtkSimplePointsReader } \\
\text { vtkSmartPointer } \\
\text { vtkUnsignedCharArray } \\
\text { vtkVersion } \\
\text { vtkVertexGlyphFilter } \\
\text { vtkXMLPolyDataWriter }\end{array}$ & $\begin{array}{l}\text { - Open point cloud } \\
\text { - Colorize the point cloud } \\
\text { - Create the viewer }\end{array}$ \\
\hline
\end{tabular}

Table 3. Examples of functionalities implemented and the libraries employed.

One of the key issues is structuring the information system, which is part of the $2 \mathrm{D}$ viewer of the hybrid viewer. The $2 \mathrm{D}$ polygons were initially vectorized in a CAD software. But after their importing in QGIS, the possible topological errors were detected and corrected. The database was created and managed through QGIS browser. In this first stage of development the database is composed by six attributes plus the primary key, namely, area (according to the site sectorization), part (each element is subdivided into different parts with its own functionalities), chronological information (year of excavation and the corresponding phase), surface (derived by the geospatial layer), and two text fields to describe more in detail the functionality and use of each area and part respectively. However, it is still open to add more relevant information for the stakeholders.

The other component of the hybrid viewer, is the $3 \mathrm{D}$ viewer. It allows to show different 3D product according to the final user, mainly point cloud and CAD reconstructions form an anastylosis process. The $3 \mathrm{D}$ elements visualization is linked to the $2 \mathrm{D}$ components by the sector attribute (named area) of the geodatabase.

One of the key issue is the presentation of the information. The final user may be overwhelmed by the large amount of information generated and be at risk of not being able to exploit it in an appropriate manner (Rodríguez-Gonzálvez et al., 2012). For this reason, the hybrid viewer will provide different interfaces according to the final user profile.

\section{EXPERIMENTAL RESULTS}

The image-based modelling of the archaeological site was planned with the aim to provide, not only the cartographic material to the local authorities for heritage conservation purposes, but also to put in value the archaeological settlement. A total of 268 images were acquired following the pipeline described in section 3.1. as well as the ground measurements to scale the points clouds. Thirteen photos were discarded due to its low radiometric quality, e.g.: hotspots. A summary is provided in Table 4.

\begin{tabular}{lcc}
\hline \multicolumn{1}{c}{ Area } & $\begin{array}{c}\text { Acquired } \\
\text { photos }\end{array}$ & $\begin{array}{c}\text { Oriented } \\
\text { photos }\end{array}$ \\
\hline Domus (townhouse) & 55 & 52 \\
Insulae (separated houses) & 86 & 80 \\
Thermae (thermal baths complex) & 72 & 72 \\
Tetrapylon & 27 & 27 \\
Forum & 28 & 24 \\
\hline
\end{tabular}

Table 4. Image distribution.

As commented above, the orientation process was carried out in an incremental way due to the repetitive pattern and lack of features in the areas with fewer remains. The obtained products, global and partial point clouds and the anastylosis results (Figures 5 to 7), were combined in the implement archaeological hybrid viewer, which is shown in the following figures (Figure 8 and 9).

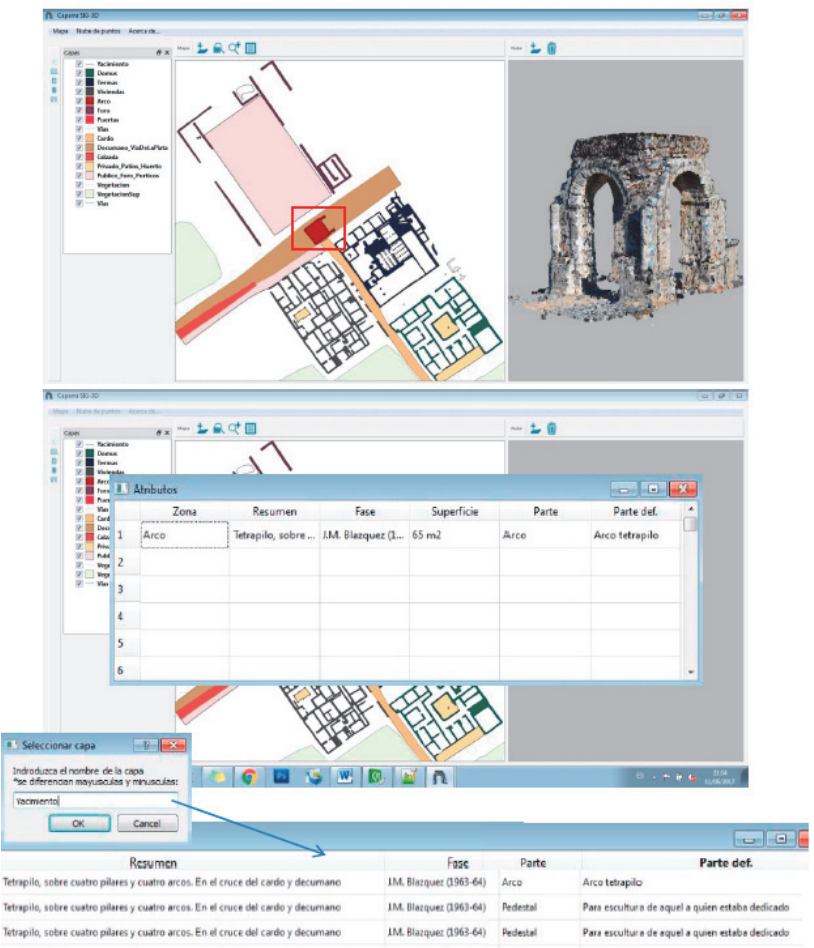

Figure 8. Example of the viewer, and the addition of attributes to the geodatabase.

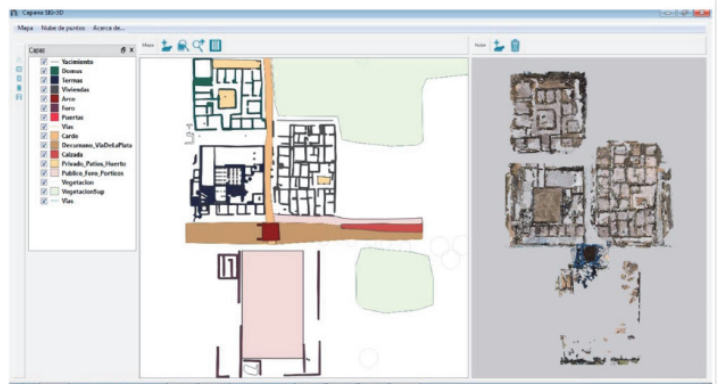

Figure 9. Graphical interface of the hybrid viewer. 
One of the aimed functionalities was to provide different tools suited to the final user profile (Figure 10). Currently, two different roles are supported in the viewer, basic (dissemination purposes) and advanced (manage and research purposes). The advanced user could access attributes, layers and point cloud, and extras functionalities such us adding layers, measuring... In contrasts a normal user, for example a site visitor, will access a simpler application in which the 2D with layers of recommended itineraries, and at the same time visualize the $3 \mathrm{D}$.

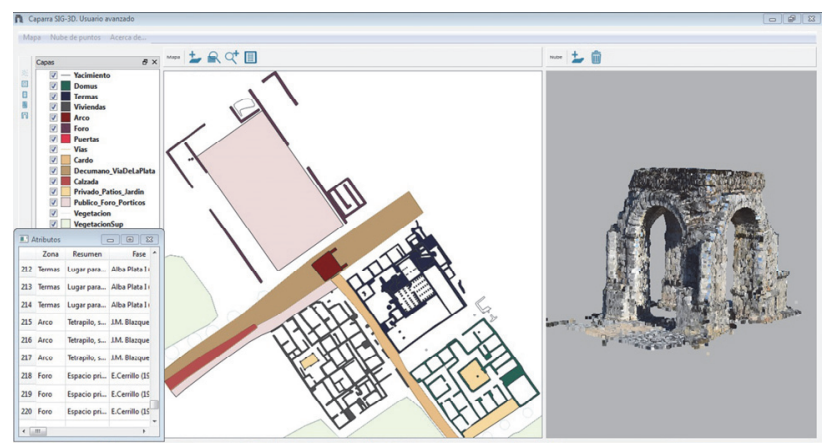

(a)

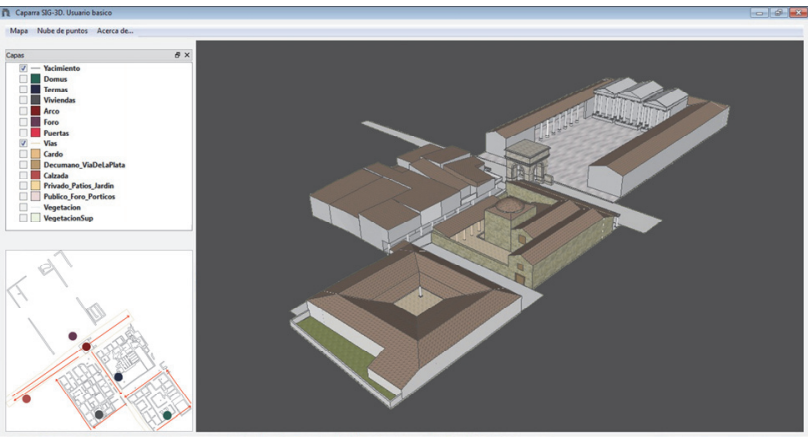

(b)

Figure 10. Different user interfaces of hybrid viewer according to the user profile: (a) advanced and (b) basic.

Finally, in Figure 11 is show the connection of the geospatial database by means of a WMS. Since the database is independent the hybrid viewer, it is also possible to employ and/or analyse part of the data (2D components) by means of other tools.

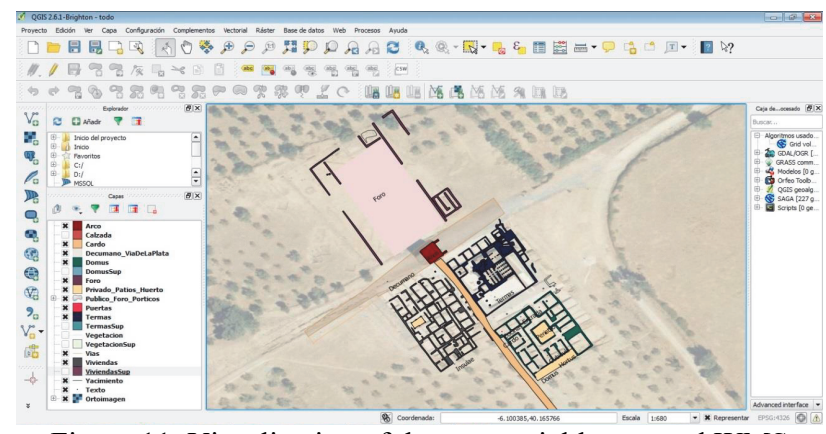

Figure 11. Visualization of the geospatial layers and WMS services in QGIS.

\section{CONCLUSIONS}

After the development of the project, the objectives defined have been fulfilled: an archaeological site survey has been executed by photogrammetric means; from it, a set of Geomatic products of great utility for technicians and for the general public has been obtained, due to the informative character of some of them; finally, everything has been integrated into a three-dimensional archaeological information system. The hybrid archaeological viewer designed allows a metric and quality approach to the scientific analysis of the ruins, improving, thanks to the implementation of a database, and its potential for queries, the benefits of an ordinary topographic survey.

As future perspectives indicate the preparation of other thematic maps such as those shown here in response to the needs of disclosure or communication is a fact that is taken for granted, here a sample has been drawn up. Regarding the application, it could be improved by adding some editing tools, to get beyond the data viewer. And above all, it seems very interesting the possibility of converting the application into a multiplatform application, that is, it could also be used in mobile phones, especially in order to reach people and in line with the actions being developed in the environment of the Via de la Plata, putting value and conversion into tourist-cultural products. It is very clear that nowadays everything that you can see and consult on your mobile phone turns out to be even more attractive.

\section{REFERENCES}

Agisoft, 2018. Photoscan version 1.3.1. Retrieved from www.agisoft.com/ [Accessed 14th of March 2018].

Belloso, M. L. 2007. El proyecto Alba-Plata (1998-2004): ruta patrimonial de Extremadura. Revista de estudios extremeños, 63(2), pp. 585-597.

Blázquez, J. M., 1996. Cáparra II, Excavaciones arqueológicas en España. Ministerio de Educación y Ciencia, Dirección General de Bellas Artes, Servicio Nacional de Bellas Artes, Madrid, Spain, 54, pp. 4-12.

Cerrillo, E., Bejarano, A., Gómez, J. C., 2000. Proyecto de excavación, consolidación y adecuación del yacimiento Cáparra y la Granjuela y la construcción de un Centro de Interpretación, Mérida. Ciudad y patrimonio: Revista de arqueología, arte y urbanismo, 4, pp. 137-141.

CloudCompare, 2018. Version 2.9.1. [GPL software]. Retrieved from http://www.cloudcompare.org/ [Accessed 14th of March 2018].

Fernández-Hernandez, J., González-Aguilera, D., Rodríguez-Gonzálvez, P., Mancera-Taboada, J., 2015. Image-based modelling from unmanned aerial vehicle (UAV) photogrammetry: An effective, low-cost tool for archaeological applications. Archaeometry, 57(1), pp. 128-145.

Floriano, A. (1944). Excavaciones en la antigua Cappara ("Cáparra", Cáceres). Archivo Español de Arqueología, 17(56), pp. $270-286$.

Grussenmeyer, P., Landes, T., Voegtle, T., Ringle, K., 2008. Comparison methods of terrestrial laser scanning, photogrammetry and tacheometry data for recording of cultural heritage buildings. International Archives of Photogrammetry, 
Remote Sensing and Spatial Information Sciences, Beijing, China, Vol. XXXVII, Part B5, pp. 213-218.

Nocerino, E., Menna, F., Remondino, F., 2014. Accuracy of typical photogrammetric networks in cultural heritage $3 \mathrm{D}$ modeling projects. The International Archives of Photogrammetry, Remote Sensing and Spatial Information Sciences, Riva del Garda, Italy, Vol. XL-540, pp. 465-472.

Nocerino, E., Menna, F., Toschi, I., Morabito, D., Remondino, F., Rodríguez-Gonzálvez, P., 2018. Valorisation of history and landscape for promoting the memory of WWI. Journal of Cultural Heritage, 29, pp. 113-122.

PNOA, 2018. Spanish national plan of aerial photography. http://pnoa.ign.es/caracteristicas-tecnicas/ [Accessed 14th of March 2018].

QGIS development team, 2018. QGIS geographic information system. Open source geospatial foundation project. http:// https://www.qgis.org/ [Accessed 14th of March 2018].

Qt, 2018. Cross-platform software development for embedded $\&$ desktop. https://www.qt.io/ [Accessed 14th of March 2018].

Rodríguez-Gonzálvez, P., Mancera-Taboada, J., González-Aguilera, D., Muñoz-Nieto, Á., Armesto, J., 2012. A hybrid approach to create an archaeological visualization system for a Palaeolithic cave. Archaeometry, 54(3), pp. 565580 .

Torres-Martínez, J. A., Seddaiu, M., Rodríguez-Gonzálvez, P., Hernández-López, D., González-Aguilera, D., 2016. A multidata source and multi-sensor approach for the $3 \mathrm{D}$ reconstruction and web visualization of a complex archaelogical site: The case study of "Tolmo De Minateda". Remote Sensing, 8(7), 550.

Schroeder, W., Martin, K., Lorensen, B., 2006, The visualization toolkit (4th ed.), Kitware. New York.

VTK, 2018. The visualization toolkit. https://www.vtk.org/ [Accessed 14th of March 2018]. 